Meta

Journal des traducteurs

Translators' Journal

\title{
Translation and Science
}

\section{Sundar Sarukkai}

Volume 46, numéro 4, décembre 2001

URI : https://id.erudit.org/iderudit/004031ar

DOI : https://doi.org/10.7202/004031ar

Aller au sommaire du numéro

Éditeur(s)

Les Presses de l'Université de Montréal

ISSN

0026-0452 (imprimé)

1492-1421 (numérique)

Découvrir la revue

Citer cet article

Sarukkai, S. (2001). Translation and Science. Meta, 46(4), 646-663.

https://doi.org/10.7202/004031ar

\section{Résumé de l'article}

Le discours et la pratique scientifique sont indubitablement liés à la traduction ; la nature multi-sémiotique des textes scientifiques les rendent prégnants. Même au niveau fondamental, la science n'est possible que parce qu'elle voit le monde comme le donné originel. La réponse de la science partage des traits communs avec les préoccupations de la traduction. Dans cet article, les liens entre les diverses idées conceptuelles de la traduction, tirés de la littérature, de la philosphie et de la science sont décrits.
Ce document est protégé par la loi sur le droit d'auteur. L’utilisation des services d’Érudit (y compris la reproduction) est assujettie à sa politique d'utilisation que vous pouvez consulter en ligne.

https://apropos.erudit.org/fr/usagers/politique-dutilisation/ 


\title{
Translation and Science
}

\author{
SUNDAR SARUKKAI \\ Indian Institute of Science Campus, Bangalore, India
}

\begin{abstract}
RÉSUMÉ
Le discours et la pratique scientifique sont indubitablement liés à la traduction; la nature multi-sémiotique des textes scientifiques les rendent prégnants. Même au niveau fondamental, la science n'est possible que parce qu'elle voit le monde comme le donné originel. La réponse de la science partage des traits communs avec les préoccupations de la traduction. Dans cet article, les liens entre les diverses idées conceptuelles de la traduction, tirés de la littérature, de la philosphie et de la science sont décrits.
\end{abstract}

\begin{abstract}
Both the discourse and practice of science are fundamentally related to the idea of translation. The multi-semiotic nature of scientific texts makes this explicitly visible. Even at the foundational level, science is possible only because it sees the world as the given original; the response of science to the original-world shares common features with the concerns of translation. In this paper, the connections between the various conceptual ideas of translation, drawn from literature and philosophy, and science are described.
\end{abstract}

\section{MOTS-CLÉS/KEYWORDS}

conceptual ideas, philosophy, practice of science, scientific texts

The theme of language in relation to science can be developed in different ways. An interesting and potentially useful thematization is through the idea of translation. The notion of translation occurs sporadically in philosophy of science, but much of this literature merely glosses over the issue of translation. Even where translation is explicitly invoked, it is mostly understood in terms of what is usually called the naïve view of translation. Such an approach does not do justice to the philosophical complexity inherent in the idea of translation. It is by paying heed to the complexities inherent in the 'idea' of translation, that one realizes the intrinsic link between science and translation.

Similar to the suspicion which science has towards language, language itself harbors a suspicion towards translation. This has contributed to the view that translation is essentially a secondary activity, derivative and dependent on the idea of an original text. As much as the scientific discourse likes to believe that it can distill ideas outside the purview of language, so does the naïve view of translation believe that translations only change the language of the text but continue to keep its 'essence' intact. These beliefs reinforce the naïve view of translation, which, according to Andrew Benjamin (1989: 60), has 'two dimensions':

First it involves the idea of recovery; of the recovery of a meaning, or truth, and the subsequent re-expression of what has been recovered. Second this understanding of translation also involves the idea of free exchange; of an unmediated and unrestrained economy in which signifiers are the object of exchange. 
As mentioned earlier, the idea of translation can be found in the discourses on science, as in history and philosophy of science, although it has not inspired the detailed discussion that it should have. In the context of interpretation, there has been a more sustained engagement with this issue that has led to a substantial body of work on hermeneutic approaches to science. ${ }^{1}$ Here the idea of translation is implicit. Science is seen as reading the book of nature. This reading immediately implies the notion of translation and interpretation, which are usually used interchangeably in this context. Translation has also been explicitly invoked in the context of the incommensurability thesis. ${ }^{2}$ This thesis responds to the belief that theories in science are 'built' upon each other, thereby implying that the concepts and entities referred to in one theory remain the 'same' when used in another theory, although in a different context. Incommensurability about theories maintains that it will not be possible, in general, to translate a term from an old scientific theory to a new one, if by translation is meant the complete carryover of meaning in these terms.

In the context of comparing paradigmatically different theories, Kuhn (1979: 202) states, "Briefly put, what the participants in a communication breakdown can do is recognize each other as members of different language communities and then become translators." He goes on to suggest a psychologistic 'use' of translation by which communities overcome 'differences' by looking for shared vocabularies. This approach will enable 'translation' from one theory into another. He further adds that this is what the "historian of science regularly does (or should) when dealing with out-of-date scientific theories" (202).

The idea of translation invoked here is problematical and does not even begin to address the substantive issues connected with it. And as Buchwald (1993) notes, such a neat picture does not seem to be tenable. He points out that the presence of intranslatability was clearly evident in Hertz's attempt at understanding Maxwell's ideas about charge and electricity. He uses this example to argue that even with this intranslatability, "Hertz was convinced that Maxwell did make consistent sense" (189). In essence, he dismisses the problem of translation and replaces it with the act of expropriation, which he sees as an activity which "regularly occurs in science" (192). But Buchwald does not address the presuppositions behind the act of translation nor does he acknowledge the complexity of translation itself. As with Kuhn, this view of translation is naïve in the sense described above.

Galison (1997: 47-50, 803, 816) offers a more sustained critique of the idea of translation in science, both at the level of discourse and praxis. Instead of a model of translation, he suggests that it is the formation of languages at the boundary of different disciplines that is relevant. He concludes that it is the notion of trading that illustrates the way scientific communities interact and languages so formed at the boundaries are more in common with languages like Creole and pidgin. But his reading of translation is also limited as attested to by his comments that the idea of temporality is not captured in the model of translation. He also believes that translation is insensitive to the sociological issues pertaining to the dynamics of language. These are contentions that a serious view of translation will not allow. The link between translation and science that I develop below will make this explicit.

It is clear that there has been minimum engagement between the discourses of translation and those of science. Also, this engagement, when it occurs, has been overshadowed by a dominant emphasis on the naïve view of translation. Fundamental 
philosophical and literary considerations of translation are completely absent in these approaches. This is surprising, because translation is at the heart of the scientific discourse. This is so for a variety of reasons. The multisemiotic nature of scientific texts makes this clear at the level of texts. The complexity involved in reading and writing these texts also involves moving from one language system to another. The presence of translation in these activities should be made visible and its consequences exhibited because it informs us about the possibilities of the formation of the scientific discourse itself. The philosophical foundations of science are also related to the ideas of translation. Science attempts to write the text of the 'original' world. The notion of 'original' is central to both translation and science. It is the response to the 'call' of the original that creates the discursive structure of science, including the manifestation of categories like verification and approximation. Even philosophy of science, placed as it is between two distinct discourses, philosophy and science, is a discourse which has to constantly engage with the problems of translation. Contemporary theories of translation, drawing upon the experiences of translators and also philosophical reflections on it, suggest new categories through which we can understand science, both as writing and praxis.

The fundamental presupposition of translation - the translatability of texts-is itself under question, not just at the level of practice but also at the conceptual level. But this does not imply the impossibility of translation. As translators have long showed, there are various ways by which one can approach translation of particular texts and specific genres. In this paper, I shall attempt to articulate some ideas on translation drawn from literature and philosophy and exhibit their relation to the scientific discourse. The division is not one of disciplines. It is more a division that arises as a consequence of a demarcation in terms of 'theory' and 'practice.' In exhibiting these categories involved in the idea of translation, I hope to map the common topography that science and translation share.

\section{Literature, translation and science}

Jakobson (1966: 232-239) identifies three types of translation. The first is 'translation' within the same language, referred to as intralingual translation. We are immersed in this kind of translation whenever we use different words and phrases to communicate similar meanings. Translation within the same language also shares this problem of 'equivalence' prevalent in translation from one language to another. Jakobson points out that even synonyms do not capture 'equivalence' of words. Thus when we replace one word by its synonym we are already giving into the mode of translation. In the case of scientific discourse, the problems associated with theory incommensurability arise out of intralingual translation. Although theories may use words and terms in the same language, and in fact carry over the same words into different theories, the incommensurability may arise because of changing historical and differing social contexts in which the words first gained currency.

The second type of translation is interlingual translation. This is what we commonly understand as translation, where translation involves rewriting a text in one language into another. Thus interlingual translation converts a text written in the source language (SL) to one written in the target language (TL). The problems associated with this form of translation are numerous. It is well illustrated in the simple 
example of translating yes and hello to equivalent words in French, German and Italian. This task, although seemingly simple, is filled with difficulties, even though "all are Indo-European languages, closely related lexically and syntactically, and terms of greeting and assent are common to all three" (Bassnett, 1991: 16). Both 'yes' and 'hello' are used in very specific contexts. In languages other than English, they convey very different meanings. For example, in the case of 'hello', it is pointed out that English does not distinguish between face to face greeting or that on the phone, whereas the other three languages explicitly make this distinction (Ibid., 17).

The third type of translation is intersemiotic translation, "an interpretation of verbal signs by means of signs of nonverbal sign systems." Although this seems to be of little interest to the practitioners of translation, this is closer to the translation mode present in the reading of scientific texts that are essentially multisemiotic in character.

What unites these three different activities into a common category of translation? Jakobson identifies the problem of 'complete equivalence' as a common category, which is never possible in any of these three types. This idea of complete equivalence, as also the notion of faithful translation, has been the bane but also the stimulus towards generating more complex theories of translation. All these three types are concerned with the notions of identity and change, whether it be the search for synonyms (re-wording), or finding other appropriate expressions in another language (re-writing). This suggests that the primary impulse to an activity we would name as 'translation' should first respond to an already-given, to an original. The concerns with equivalence and faithfulness arise after the initial acknowledgement of the original. It is this primary impulse which also allows us to gather the activity of science under the name 'translation,' where the 'original' is the world as presented to us.

All these three types of translation can be clearly discerned in the scientific discourse. Although there is a predominance of translation in the discourse, there is almost no acknowledgement of this process. This is indeed startling and suggests that science must have strategies to erase this domineering presence of translation in its activities. This would then imply that there is always a meta-discourse on translation, which the scientific discourse holds, upon which the erasure of translation is itself based. The success of science in erasing the presence of translation has lessons for both science and translation.

First, consider intralingual translation. As I mentioned earlier, the incommensurability thesis is most closely concerned with this form of translation. The central argument against this thesis is related to the position that words that refer to objects allow the possibility of a common reference in different theories. Making these words function as 'names' seemingly erases the problem of equivalence among words. Although the problems of translation are invoked in this thesis, it is also diluted by the emphasis on reference and the possibility that proper names function 'outside' translation.

The case of interlingual translation in the context of scientific discourse is also interesting. Although, globally, the scientific discourse is increasingly written in the language of English, that was not always the case. Pioneering work in modern physics, including Einstein's papers on relativity, was largely written in German. Russian mathematicians, as also their physicists, wrote almost exclusively in Russian. There has also been a large body of work in French, both in mathematics and physics. It is 
indeed remarkable that these diverse texts in different languages have all been rewritten and expressed in one language, English, with scarcely any mention of the problems present in translating from one language into another! ${ }^{3}$ The facile acceptance of quantum and relativity theories, for example, without any mention of the problems of translation is remarkable for it points to the insistence by which science ignores the claims of translation. Why should the problems of translation not be present in translating scientific texts from German to English? Are the problems of equivalence, faithfulness, communication of meaning and so on not present in these texts? Or is it that they are seen to be unimportant in the context of science? If so, who makes this judgement? And why?

The neglect of translation in the re-writing of scientific texts is due to many reasons. Let me focus on one reason that recurs repeatedly in our understanding of the scientific discourse and which is related to a view of natural language that science holds. In theoretical texts, as in quantum and relativity theories, it is presumed that the 'essential' content of the text is contained in the mathematical sub-text. The natural language component of the text, whether in German or English, is seen not to have 'substantial' content as far as the meaning of that texts is concerned. This is also emphasized in the text in the form of the mathematical equations that remain the same whether the theory is written in English or German. And since these equations carry the 'essential' content, what does it matter what natural languages one uses? This is, roughly, the argument that explains science's total disdain for the concerns of translation. I shall not develop a response to this now; here, I merely want to mention that scientific texts are beholden to both mathematical and natural language sub-texts. And the concerns of translation are also not indifferent to mathematics. ${ }^{4}$

This argument is also related to the third kind of translation, namely, intersemiotic translation. I think it is clear that in the case of mathematics, there is always the 'presence' of translation in the way we continuously interpolate from symbols to natural language. The semiotic system of mathematics does not derive any meaning without prior reference to natural language. In reading and writing the scientific text, there is always a movement from one semiotic system to another. There is no other mechanism, other than translation, that can effectively explain how it is possible for us to generate 'coherent' meaning of such texts. This will then imply that a scientific text, which glosses over the issue of translation in order to present a 'unified' text as if the problems of translation across different semiotic systems are absent, is only one translation among many other possible translations. The use of diagrams, figures, tables, charts and so on in the scientific discourse also relates the scientific activity to the concerns of intersemiotic translation.

Since translation is translation of an original, the ideas of equivalence between the translated and original text arise naturally. There have been many attempts to find criteria for equivalence. As is well known, even word for word equivalence is problematic. The referential aspect of a word creates one possible criterion for equivalence, which is usually called denotative equivalence. ${ }^{5}$ Equivalence can also be on the order of connotation, formal, pragmatic and so on. It may also be desirable to go beyond the orbit of the text and search for the notion of equivalence in the agency of the reader and the different cultures involved in translation. Nida's (1964) idea of dynamic equivalence, for instance, argues for a notion of equivalence based on the 'equivalent' effect of the text on the reader. 
In his influential work, Popovic (1976) distinguishes between four types of equivalence arising in translation-Linguistic, Paradigmatic, Stylistic and Syntagmatic. Related to this is his emphasis on the 'invariant core' in each text, suggesting that translation function to transmit and transfer this core. The idea of invariance is very suggestive of its uses in other disciplines, particularly science. Invariance is essentially a concept associated with dynamics and change. It is only under the agency of some action that we can recognize the invariance of an object or system. Invariance is, therefore, specifically linked to an act as also to that element, in part or in full, which remains invariant. In the case of translation, the specific dynamic act is that of translation. Under this action, it may be believed that 'something' remains invariant, perhaps the meaning of the text. The text by itself cannot be invariant, nor can the number of words or pages. This idea of invariance has striking philosophical similarities to the notion of invariance as it occurs in science. As is well known, the idea of symmetry in science is deeply implicated in the idea of invariance. Although I do not mean to suggest a facile analogy between the two, I mention this merely to draw attention to the close conceptual links between the concerns of translation and of science. In all these three types of translation, the problems of equivalence, identity and sameness are present.

It is important to emphasize here that the scientific discourse is not totally distinct from literary discourse. As a discourse, it has its own stylistics, aesthetics, rhetoric, metaphors and so on. ${ }^{6}$ But it also has something more-it is this extra space which needs to be delineated clearly. The nature of the scientific discourse, as a multiple semiotic system and in its use of multiple literary strategies, is already implicated within the notion of translation. Setting out some salient points related to translation, derived from the concerns of literature, will help broaden the understanding of the scientific discourse, as manifested in its written form. This task is indeed urgent considering the widespread belief that scientific and technical texts do not exhibit the problems present in literary translation. Even Susan Bassnett (1991: 79), who otherwise champions the need to acknowledge the complexity of translation, has this to say about scientific texts:

If the text is perceived as an object that should only produce a single invariant reading, any 'deviation' on the part of the reader/translator will be judged as transgression. Such a judgement might be made regarding scientific documents, for example, where facts are set out and presented in unqualifiedly objective terms for the reader of SL and TL text alike, but with literary texts the position is different.

This privileging of the scientific text is unnecessary and also untenable. Ironically, the sentence following the above quote is, "one of the greatest advances in twentiethcentury literary study has been the re-evaluation of the reader" (Ibid., 79). This shift to the reader reinforces the complexity that is inherent in scientific texts, which attain this status by being read as such. Barthes' view of the reader as a producer of the text, and not merely a consumer, along with Kristeva's (Ibid., 79) positioning the "reader as realizing the expansion of the work's process of semiosis" are comments equally applicable to the scientific discourse. In fact, this constant schizophrenia of reader/translator is a defining mark not only of translation but also of the scientific activity. If translators are readers of the source text that they translate, scientists are readers of the 'book of nature' which they then translate. 
There is no getting away from the textual character of science. Being a collection of texts, written in natural and symbolic languages, there are various factors which regulate its form and, not so obviously, its content. It would be easy to say that scientific texts form one uniform genre. But like poetry and fiction, the boundaries defining the genre are constantly under pressure to change. Thus although texts can be 'identified' as belonging to the scientific (and/or technical) genre, this does not negate the possibility of overlaps with those characteristics which mark literary genres.

This intermarriage of different genres creates further problems, as far as translation is concerned. Each genre deals with the concerns of translation in different ways. Translators, drawing upon the practice of translating texts, have attempted to set some basic rules of translation for different genres. Lefevere's (Ibid., 81) seven strategies for translating poetry and Hilaire Belloc's (Ibid., 85) six general rules for translating prose are attempts in this direction. These strategies respond to the textuality specific to these different genres. Although, at this point, I do not believe that one can attempt a similar exercise for scientific discourse, more detailed analysis of that discourse might lead to such attempts in the future. Here I will only assert that the writing of the scientific discourse already, and implicitly, involves discursive strategies dealing with translation.

Most, if not all, scientific texts are 'structurally similar' to prose texts. The text is bifurcated into chapters, sections, paragraphs and sentences. There is an apparent linearity to the text-the development of the text beginning with simple ideas and equations and proceeding to more complex physical (and mathematical, if required) problems and solutions. The first chapters are literally the foundation upon which the edifice of the text rests. In the text, we can find claims, arguments, proofs, suppositions, references and so on. All these elements go to constitute the style of the genre itself. Thus the process of translation has to negotiate with, build upon and integrate all these elements. It is also the case that the possibility of research itself is based on the ambiguities inherent in the activity of translation.

In spite of translation being one of the oldest professions in the world (or maybe because of it!), Venuti (1998: 8) observes that the "study of the history and theory of translation remains a backwater in the academy." This observation points to a fundamental tension present in according due importance to the study and practice of translation, and highlights the need for a sociological perspective, which is already inherent in this activity. It also suggests an expansion of the academic stakes in translation. In particular, one can read Venuti's Scandal of Translation as a sign of growing pains. As a sign of the times, too, Venuti uses translation as a prism through which larger sociological issues are articulated.

My focus on Venuti's book here is an act of appropriation of certain conceptual categories that well suit my own reading and re-writing of the scientific discourse. That they are 'sociological' makes it all the more relevant, because it allows me to connect this discourse naturally with issues in sociology of science and place them within the gambit of translation. Since my reading of Venuti is an explicit mode of appropriation, let me isolate two categories, minor literature and authorship, that he discusses in detail and which are also useful for understanding the scientific discourse.

Minor Literature: Venuti (1998: 10) begins with the theme of minor literature, which reflects his personal preference to "translate foreign texts that possess minority 
status in their cultures." As a translator, he does not hold the position that language is "simply an instrument of communication." Rather, he begins with a view of language as a "collective force" with "diverse cultural constituencies and social institutions." There is a hierarchy in this diversity with the "standard dialect in dominance." But the standard dialect has to negotiate constantly and interact with the "regional or group dialects, jargons, cliches and slogans, stylistic innovations" and so on. These are minor variables that dynamically constitute the language and, furthermore, "subvert major form," thereby "revealing it to be socially and historically situated" (Ibid., 10). Literary works can give into this majoritizing influence of the dominating aspect of the language and culture or they can increase the "radical heterogeneity by submitting the major language to constant variation." In doing this, the literary work may succeed in releasing the 'remainder,' through which a minor literature "indicates where the major language is foreign to itself" (Ibid., 10).

Although the above remarks may seem to apply to very particular instances of literary texts that embody a minor literature, the issues they generate are relevant to a more critical understanding of reading, writing and translating. The emphasis on the minor, as forms of language and culture, responds to an integral aspect of all languages, namely, the tendency present in writing to gather around the domineering presence of the 'majority' and a concomitant subjugation of the minor voices. It needs a conscious act to release the minor from the overpowering presence of the major. This attempt to consciously release the remainder and to let the 'minor' exhibit itself introduces an 'ethics' of translation. Thus he notes (Ibid., 11),

Good translation is minoritizing: it releases the remainder by cultivating a heterogeneous discourse, opening up the standard dialect and literary canons to what is foreign to themselves, to the substandard and the marginal.

Explicitly invoking the foreign is a strategy that I find useful in a discussion of the scientific discourse. 'Foreign' is not just the site of a different language. Being foreign is not merely being different. It also suggests a perpetual possibility of conflict and a 'distance' that can never get assimilated entirely. The relevance of this to scientific discourse is immediate. The view of natural language (NL) in the scientific discourse is strongly suggestive of its role as a minor language in the dominant culture of scientific 'language.' Attesting to this is the belief that literary strategies, such as the use of metaphors and rhetoric are not 'part' of science but rather belong to the baggage of NL which is taken as a reluctant partner in the scientific discourse. The discourse always attempts to attain and sustain discursive homogeneity. Heterogeneity, in the context of opening up the foreign, is a problematic task in this discourse. The relevance of NL sub-text, as minor literature, and the inhering presence of the foreign within the scientific discourse can only be released through attempts at translation.

What else constitutes the foreign for the scientific discourse? I think it can be persuasively argued that the discourses of history, philosophy and sociology of science constitute the foreign, in the context of being a minor literature in a dominant major (scientific) culture. The repeated suspicion of scientists towards the relevance of these fields, in the context of scientific practice, is a pointer to this. ${ }^{7}$ As mentioned earlier, the presence of literary elements within the discourse, conceptual ideas like subjectivity and cultural mediation are seen to be outside the orbit of this discourse. 
The literary elements are seen to constitute the space of jargons, cliches, dialects and so on of the scientific discourse. All these together form the 'foreign' as far science is concerned. The priority given to mathematics and the repeated attempts to claim that the language of nature is mathematics, only succeeds in bracketing natural language as a tongue of the foreign within this discourse.

I am even prepared to go to one end of the spectrum to say this: it is only through acknowledging ideas of translation in the scientific discourse that the presence of the foreign can be made visible and legitimate. The suspicion of science towards language can now be expressed as a suspicion towards the heterogeneity of language. Venuti's shift towards minor literature and the exhibition of the remainder are precisely what counter this suspicion and allow the heterogeneity of language and culture to be made explicit in the scientific discourse. In this context, it is worth recollecting Walter Benjamin's citation of Rudolf Pannwitz (Benjamin, 1992: 81):

The basic error of the translator is that he preserves the state in which his own language happens to be instead of allowing his language to be powerfully affected by the foreign tongue... He must expand and deepen his language by means of the foreign language.

Authorship: Venuti explores the idea of authorship in the context of translation. I isolate this category mainly because the scientific discourse has a unique engagement with the idea of authorship and its association with the notion of original. This engagement once again reinforces the intrinsic link between science and translation. The issue of authorship is significant in the formation of the scientific discourse. The world is the original, the touchstone around which scientific discourse emanates and by which it is sustained. The idea of authorship that derives from being associated with this given original is quite different from that of literary texts. It is in this sense that scientific discourse is always derivative and always a translation. Authorship in science, both in its writing and practice, mimics the secondary role it holds for translators. The scientists are never the original authors. They can only write, rewrite and translate the world as original. The first authorship, the one who holds the copyright over the translation, is the world. Scientific discourse only opens up the text of the world, one that is already 'written.'

I will discuss this issue through the literary form known as 'pseudotranslation,' because it allows me to exhibit the unique relationship between science and authorship. In order to expose the lack of critical engagement with the foreign, Venuti (1998: 33) introduces the discussion of pseudotranslation, which is "an original composition that its author has chosen to present as a translated text." In the field of translation, such a move is useful, "since it involves a concealment of authorship," which, "inevitably provokes a reconsideration of how an author is defined in any period, leading either to a reactionary imposition of the dominant conception or to an unsettling revision that sparks new literary trends" (Ibid., 34).

Something similar happens constantly in the scientific discourse. The claims of science, as far as authorship is concerned, are articulated in the following manner. The world is the original author. Science merely speaks that which is already written in the text of this world. Thus science and scientists abdicate the responsibility that is due to the original author. This also implies that science speaks for the world and does not, by itself, add anything to what the world says. Therefore, the scientific narrative of the world is not a construction of the practitioners who are embedded in a 
history and culture, but is merely a 'revelation' of the text of the world. In contrast, the sociological critique of science tries to place the responsibility of the discourse on the scientists themselves by suggesting that scientific discourse is co-constituted by their narrative of the world, which is 'contaminated' by the historical and cultural positions they embody.

As far as the question of authorship is concerned, the scientific discourse presents itself on the order of pseudotranslation. The traditional displacement of the author in scientific texts, and the cultivated image of the discoverer as one who merely speaks about the wonder of nature, are best captured by this image of pseudotranslation. Pseudotranslation implies an abdication of responsibility. It also bestows an ability to say something on somebody else's behalf. The discourse on technology, by scientists and technocrats, follows a similar argumentative pattern. The explicit realization that scientific narrative should be seen as pseudotranslation implies that this narrative of the scientists should itself be acknowledged as 'original' rather than displace this 'originality' to the voice of the world. If this position of the scientific discourse as pseudotranslation is tenable, then it would be more in tune with the claim that scientific narrative is one narrative of the world; one translation of the world.

The final category that I want to introduce here, in the context of the link between science and literary concerns of translation, is the notion of dubbing. The process of dubbing is predicated on a particular conception of language and its relation to pictures. Dubbing is usually a process associated with filmmaking. After the film has been shot, the sound track is overlaid so that there is synchrony of sound and vision. Dubbing of films is also associated with replacing the language of the 'original' film with the dubbed language. This process of dubbing has inherent presuppositions about the nature of the original and the role of language in visual media, and is closely related to translation. ${ }^{8}$ First, the language of the original film is removed and then the soundtrack of another language superposed on the film, largely following lip synchronization. In this translation, there is the assumption that the 'essence' of the film is retained, thereby suggesting that in visual media, language plays a secondary role in comparison to the visuals. There are two themes associated with dubbing that I shall mention here, which, I believe, are related to the scientific discourse. First, is the close link between dubbing and culture, both dominant (associated with the original) and derivative (that of the translated). Inherent in this is the issue of language and its relation to the film. This link between language and film in the case of dubbing can be contrasted with the case of subtitling foreign language films. Second, the example of dubbing also illustrates something intrinsic to the nature of texts and translation, and is related to the possibility that texts are multi-layered. This is obvious in the case of visual texts, but the possibility that there are 'multiple layers' even in written texts cannot be easily discounted. If there are multiple layers in a text, then what does the translation of a text mean? Does it imply that all the layers have to be translated simultaneously? Or is it that only those parts of the text implicitly associated with language should be translated?

These questions are important in articulating the link between science and translation. The scientific text is itself multi-layered in that it is primarily multisemiotic. In moving from one semiotic system to the other, the activity of dubbing is present. Dubbing does not occur across the expanse of the text, but only in certain 
parts of the text. Labeling of diagrams, figures and tables, for example, is similar to the process of sub-titling. Just as language is changed but the visuals are retained in dubbing, mathematical equations are many times retained but the 'language' related to the specific problems is changed. I believe that this is a fertile way of understanding how similar mathematical structures are taken over to model, describe and explain different physical situations.

The world is manifested through various means. One is by 'reading' nature; others correspond to various forms of visual presentation of the world. The world is converted to the text of science through continuous translation-at the level of language, no doubt, but also at the level of visual, auditory, tactile and other sensory media. Different scientific theories translate the world at different levels, while always 'retaining' something of the original. This is as much a reflection of the scientific discourse as it is of the world. The consequences of such multi-layered translations are crucial to an understanding of the meaning and practice of science. The different semantic domains created with the use of pictures, diagrams, geometry and mathematics, as part of the scientific texts, imply the essential multiple layering of these texts. The notions of translation and dubbing therefore play a crucial part in transmitting and communicating with such texts.

\section{Philosophy, translation and science}

What I have attempted to do in the last section is to identify central issues related to the theory and practice of translation drawn from literary translation. Since the practitioners of translation engage with particular texts and specific languages, the central issues reflect these disciplinary concerns; thus the identification of categories like equivalence, rules of translation, invariant core of texts, the idea of the foreign, minor literature, authorship and so on. These categories, derived from literature, already point to a need to go beyond a naïve view of translation. Most importantly, in the context of this paper, this expanded view of translation was shown to be of relevance to an understanding of the scientific discourse.

There are other approaches to thematizing translation that exhibit its conceptual foundations. Like other disciplines, philosophy has also not given prominence to the question of translation. In spite of Derrida’s (Benjamin, 1989: 1) declaration, "With the problem of translation we are dealing with nothing less than the problem of the passage to philosophy," and other assertions on the importance of translation by Walter Benjamin, Steiner, Quine and Davidson, among others, translation has been at the margins of philosophy. ${ }^{9}$ There are many powerful philosophical concepts embedded in this theme of translation. The philosophical concern with translation is not totally disjoint from that of the literary field. But, as with any discipline, the articulation of these concepts draws upon specific historical and social traditions. I identify a few of these concepts, which I believe are relevant to an understanding of the discourse of science and that of philosophy of science.

The idea of the original is the first defining moment of translation. The original is situated in the embodiment of the book. It is the first point of reference. All other points of reference are derivative from it. But there is also specificity to the notion of original in this context which differentiates it from any given object as original. It is the particularity of the act of translation, that which is unique to it, which makes the 
original 'original.' Original is not just a statement of transcendence. That would place it on the order of any object, translated, translatable or not. What the idea of translation gives to the original is meaning. This is first manifested in the act of reading the original with the concurrent possibility of writing what is read. This constant reading/writing creates an original that is not the mirror image of the original as 'mere' object. There is also a constant implication that the original should always be made available during the process of translation. So not only is the original transcendent, but it must be stable, must not be evanescent, must be accessible both in form and content through the length of translation. Thus it must be open to the manipulations of the translator.

The naïve view of translation, emphasizing the re-expressibility of the original and limiting the act of translation to a particular act of translating, tends to view original in terms of self-identity, but this can be accessed as such only after translation. We should also be open to the possibility that this self-identity of the original can never be grasped as such, either as the original or through the act of translation, because the original itself is "not absolutely self-identical" (Benjamin, 1989: 172). The paradox is that the original, beyond its primary object-hood, can only be given through translation, whether the original is a book, a painting or the world. ${ }^{10}$ So the concept of original whose transcendence is not in doubt but whose self-identity is, creates a space unique to translation.

The idea of the original is also the first link between science and translation. The world is the given original. The world is presented to science on the order of the original, before it can be presented as the real. This regulates the discursive strategies unique to science, which arise as a consequence of writing the text of the original, namely, the world. This also leads to the preoccupations of science with the categories of verification and approximation, and of global and local discourses. The theme of the original generates a plethora of subsidiary themes, such as translation of the original, copies of the original and so on. I believe that we can best understand the character of the scientific discourse only by first analyzing what is catalyzed by the 'call' of the original.

The relationship between the original and the translation canonically leads to an emphasis on principles of comparison. What distinguishes the scientific discourse, as translation, from the literary experiences of translation, is the articulation of specific principles of comparison, such as verification and related notions of approximation. The methods through which science has articulated its principles of comparison have lessons for translation studies also.

Suspicion of translation has a long history even in philosophy. Plato's suspicion of poetry has sedimented through the ages and has reached its peak in the rhetoric of science. Contributing to this suspicion is a popular understanding of poetry as expressive of ambiguity, largely due to its dependence on the figural at the expense of the literal. This constitution of the binary of literal and figural and the priority accorded to the literal is based on a very limited view of language.

In the conventional understanding, "the literal precedes the figural and hence is prior to it" (Benjamin, 1989: 10). A critique of this dichotomy begins by first questioning the priority accorded to the literal. In the conventional view, literal is seen as temporally prior to figural, and figural as 'something' added to literal. This suggests the possibility that 'stripping' away of that which is added will then allow access to 
the 'true' literal presence, what Benjamin refers to as the "logic of stripping" (Ibid., 11). It is in this sense that the figural becomes superfluous to the extent that it is parasitic upon the literal utterance and, more importantly, does not add anything 'essential' to the prior content.

But is this distinction tenable? Various arguments against the possibility of isolating the literal, by stripping away the figural, have been suggested. The extensive literature on metaphors strongly suggests that metaphoric utterances are all that are possible. It has been suggested that metaphors constitute the language of philosophy and that it is impossible to remove metaphoricity in order to exhibit the literal 'behind' it (Derrida, 1982). This view also suggests that it is impossible to grasp the original in its 'purity,' apart from the constitution of language. The original itself is a site of plurality and ambiguity, and it is as much the figural that allows us a hold on the original.

Thus, if it can be argued that "the literal is itself a secondary effect prior to which is semantic over-determination," then the "distinction between the literal and the figural is undermined" (Ibid., 22). This is exactly what Benjamin does by situating the prior within the plurality of the 'anoriginal.' If the original site is already a place marked by semantic plurality, then the priority given to the literal and the distinction between literal and figural cannot be sustained. Thus, for him, the literal is secondary, arising from the impossibility of understanding a homogeneous, singular identity of the original. Since the original is the site of plurality, translation explicitly becomes interpretation, and textuality emerges "as a name for the site of plurality" (Ibid., 38).

By prioritizing the literal, we make the claim that we can contain language and reduce its expressive capacity to a minimum. The need to contain language through this emphasis points to an inherent tendency in language to proliferate and be undisciplined in its articulations. This also suggests that language gravitates towards the figural and that it needs a conscious act of a critical subject, 'outside' language, to strip the figural in order to exhibit the literal. The unruliness of language generates an essential tension between language and meaning, especially in a discourse such as science that is overly concerned with meaning and truth.

Therefore, it is not surprising that the literal/figural distinction finds a most privileged position within the scientific discourse. The suspicion of language in science is in great part a suspicion of the figural. The apparent economy of this discourse arises out of continued attempts to strip the figural and isolate the literal. This can be done in two ways. The first is to decrease the use of (natural) language and keep its presence to a minimum in its discourse. The second, concurrently followed, is to introduce a 'language' which, by its very nature, articulates the presence of the literal and negates the formation of the figural. This is accomplished by the use of mathematics, and to a lesser extent, the use of other non-verbal semiotic systems as part of the scientific text.

Does science succeed in this project? Does it really obliterate the figural and exhibit the literal? To answer this question, we need to examine critically the role of language in the discourse and also respond to the claims of mathematics, especially regarding its denial of the figural. The presence of metaphors and the essential role of models in the scientific discourse suggest that science fails in its attempts to erase 
the figural. An analysis of the scientific discourse will exhibit the falsity of the first claim-namely, the ability of the discourse to rein in language and keep its figural effects to a minimum. To critically consider this position, we have to look at how science uses language in writing its texts. To respond to the second claim-the presence of metaphors in the mathematical discourse, its reference to natural language and the inherence of translation in mathematics conclusively demonstrate that even in the case of mathematics, the literal/figural distinction is difficult to maintain. ${ }^{11}$

Yet another point of commonality is semantic differential plurality that inheres in texts, whether scientific or otherwise. In the context of translation, it is this plurality that problematizes the possibility of a 'faithful' translation. Translation is "both a plurality of acts and plurality of significations" (Ibid., 30). The site of plurality is the word itself. The link with translation is a consequence of translation's attempt to 'capture' the original in another language. To be 'faithful' to the original, there is the tendency within every act of translation to reduce meaning. The search for the identity of the original and the desire to communicate the 'sameness' across two texts tend to negate the semantic differential plurality inherent in every word.

Invoking the idea of plurality, always present in the text, connects the concerns of translation explicitly with the idea of the scientific discourse. Obviously, the discursive strategies of science attempt to negate this plurality. This is accomplished by privileging definitions, replacing natural language with symbolic and mathematical language, restricting the use of natural language to refer to entities and so on. But the scientific text is primarily a text in which there is an inhering presence of this differential plurality that is manifested, expressed and suppressed in different ways.

Bringing the text and language to the fore also allows us to reflect on the multisemiotic character of the text. In particular, the 'bilingual' presence of mathematics and natural language in these texts demands an explanation of how the text constructs 'coherent' meaning. Derrida, in analyzing what it means to translate the words 'he war' in which 'war' is common to both German and English, realizes that translating words which belong to two languages opens up a 'double' sphere of semantic plurality. Ignoring this and sticking to the field of only one language succeeds in negating the original words themselves. "Translating the he war in the system of only one language is to efface the event of its mark" (Ibid., 151).

In a scientific text where there is a surplus of these multisemiotic terms, the sphere of 'double plurality' should proliferate. But, paradoxically, it seems that the presence of two languages in the scientific text actually serves to regulate and constrain meaning. This is made possible by restricting meaning in one domain while simultaneously creating multiple semantic domains. This move succeeds in creating parallel semantic realms into which the idea of plurality gets diffused. This characteristic of the scientific discourse suggests that the idea of plurality in this discourse is not only different, but also more complex, in contrast to monolingual texts. This succeeds in opening up new avenues of understanding the meaning of plurality and the place of its 'residence.'

The very possibility of translation whereby 'something' remains invariant is represented by the relationship between words and things. If a word refers to a thing, then that thing will function as a common point of comparison when the word is translated into another language. The reference of a word to a thing is accomplished, 
for example, by naming. And names, among all other linguistic objects, resist translation the most. Derrida (1985: 185) remarks that a proper noun "does and does not belong...to the corpus of the text to be translated."

This ontological association of names with things is used as a strategy that influences the topology of natural language in the scientific discourse. This discourse attempts to use natural languages largely in a referential manner. Halliday's (1988) analysis of the scientific discourse points to the preponderance of nouns over verbs and adjectives in the discourse, a phenomenon he calls 'grammatical metaphors.' This preponderance is not accidental, rather it is a by-product of a discursive strategy in which the privilege of naming is extended not only to objects but also to properties and even to events. By doing this, the question of meaning is postponed and always deferred. In the scientific discourse, we never come across the question: what is the meaning of the electron? The process of naming also does something else: "it excludes the possibility of differential plurality" (Benjamin, 1989: 156), thus creating the belief that things transcend words, and therefore that naming can diffuse the ambiguity associated with words. We should remember that in the context of translation, the ability to associate word to thing does not negate possible ambiguity. Walter Benjamin uses the example of brot (German) and pain (French), both of which 'refer' to 'bread' (English), to emphasize the point that modes of intention are different in the use of brot, pain and bread' (Ibid., 93). All these words have different meanings, although their intended object is the 'same.' This difference between the intended object and modes of intention is not absent in the scientific discourse. An 'electron,' for example, is understood differently in different contexts depending on the discipline in which it is presented, whether in classical physics, quantum physics, chemistry and so on. Although the same word is used to refer to the 'electron' as the intended object, the modes of intention are different. ${ }^{12}$

As a final detour into the arena of translation and philosophy, I shall draw upon Walter Benjamin's influential work on translation. I shall restrict myself to those ideas that will be of some relevance to my project of linking translation and science. Benjamin does not subscribe to the naïve view of translation as re-expressing an original. There is no possibility of a 'rational recovery' and we have to understand translation through an 'emphasis on text and language.'

If translation does not merely re-express an original text what else does it do? For Benjamin, the position prior to actual translation is important, because it conveys that the text is more than a text-it is a text open to translation. In this sense all texts are not translatable; not all texts can be an original. The original is that which survives, has an 'afterlife. ${ }^{13}$ It is this survival which beckons the translator and opens the text to translation. To comprehend translation, we have to first understand the original as containing "the law governing the translation: its translatability" (W.Benjamin, 1992: 71). What does translatability imply? It is seen as an "essential quality of certain works," supplies a "natural connection" to the original and suggests "that a special significance inherent in the original manifests itself in its translatability" (Ibid., 71). The translatability of a work is defined in terms of the "capacity of the work to live on." Thus, "a translation issues from the original-not so much from its life as from its afterlife" (Ibid., 72). Consider the relevance of the above views in the context of the world as original. The exemplar of an 'original' in its 'afterlife' is the world itself. The world is the first model of survival, the first model of text and 
gives the first call for translation. Science as the translation of the original world captures a "specific significance inherent in the world," that which supplies the exotic to the scientific discourse. Science responds to the law of translatability inherent in the world as original.

The idea of translation thus gives voice and expression to the original in terms of a new language. It is useful to grasp the scientist's often-quoted image of nature as an open book. Reading this book is first to translate it. A 'bad' translation only succeeds in transmitting the 'information content' but not the essence of the original work. In understanding science as being involved in the activity of translation, we are projecting the question of language to the fore. In translating the world, science also exhibits and expresses the "central reciprocal relationship between languages" (Ibid., 73). This relationship, articulated by Benjamin as a 'kinship' between languages, does not rest on a simple mimetic relation. Rather, it "rests in the intention underlying each language as a whole" (Ibid., 74). Thus if science has to be accorded the role of a 'good' translation of the world, then we have to analyze in detail the different ways in which it uses language(s) to express the world as original. As good translators, scientists must attempt not merely to transmit information but also to articulate the 'essence' of the world, and to pay heed to the 'intentions' of the languages that they use in this articulation. The claim that mathematics is the language of the world is a claim about the essential nature of the original world. But it is not obvious that the 'mathematics' of the world is itself the 'mathematics' of human beings. We should remember here that in every good translation, one is as much adding to the original as 'representing' it.

For Benjamin (Ibid., 77), the "task of the translator consists in finding that intended effect [Intention] upon the language into which he is translating which produces in it the echo of the original." It is interesting that Benjamin uses the word 'echo.' The task of the translator can only produce the echo of the original, not the originality of the original. The idea of the echo is that we hear our own voices sent back to us. The echo is never strictly identical with what has been voiced before. It also suggests something about the space, the topography, of the domain that creates the echo. The voice that comes back to us is similar to what we uttered but is also distorted by the response of what sends back our voice. Any utterance of the world, especially for science, obeys this image of the echo. The scientific expressions of the world bounce back from the world and suggest to us something about the world itself. Is it too much to believe that the relationship between scientific discourse and the world follows the orbit of the echo? Is it also an accident that the study of echo itself in science participated in the creation of the scientific discourse on sound? Is not then the task of the scientist also the task of the translator?

To understand this in detail we will have to engage with the issue of language and the multiple ways in which science constructs its languages. The emphasis on mathematics, seen as an integral part of science, obscures the kinship that it shares with natural language and also with the use of other semiotic systems like figures, diagrams, tables and so on. Here I will briefly allude to Walter Benjamin's idea of a pure language that is the 'language of truth' which points to a 'harmony' in the "relationship between the original and translation" (Benjamin, 1989: 99). This pure language does not refer to a particular language and, 
It marks the sameness of languages while allowing for their differences. What comes to be released by the translator is the language inhering in a language (Ibid., 103).

There is an intimate connection between the formulation of 'pure language' and the scientific discourse. This discourse, above all else, stakes a claim to truth, to being the discourse of truth about the world. Most important in the context of my discussion is the link between 'truth' and translatability. Walter Benjamin (1992: 82) asserts, although in the context of scriptural texts rather than the scientific one, that,

Where a text is identical with truth or dogma, where it is supposed to be the 'true language' in all its literalness and without the mediation of meaning, this text is unconditionally translatable.

This assertion, first and foremost, allows us to consider the possibility that the text of the world is 'unconditionally translatable' and that it is the task of science to play the role of the translator of this text.

\section{NOTES}

This work was supported by the Homi Bhabha Fellowship and is part of a larger work on the relationship between science, language and translation. I am indebted to Michael Weinstein for a careful reading of the manuscript and for his many suggestions. This material will appear in my book titled "Translating the World: Science and Language" published by University Press of America, Lanham, to appear, 2002.

1. There is appreciable literature on this topic. For example, see Heelan (1983), Crease (1997).

2. For a detailed discussion on this thesis, see Sankey (1994).

3. Scott Montgomery (1996) discusses the case of Japanese science and the politics of translation associated with it.

4. A more detailed discussion of this link is available in an unpublished paper of mine titled "Mathematics, Language and Translation."

5. The Routledge Encyclopaedia of Translation Studies (1998) offers a comprehensive account of the different categories associated with translation.

6. There are many books that deal with this topic. For example, see Wells (1996), Locke (1992), Gross (1990).

7. For example, the prominent physicist, Weinberg, says that philosophy of science is "at its best" a "pleasing gloss on the history and discoveries of science." Quoted in Marsonet (1995: 35).

8. The Routledge Encyclopaedia of Translation Studies (1998: 74-76) has a section on dubbing and translation.

9. For more detailed discussions on this point, see Steiner (1975), Gentzler (1993).

10. It might be argued that various other possibilities like commentary, adaptation etc., are also in a relationship with the original. The distinction between translation and these other activities cannot be strictly drawn. See Routledge Encyclopaedia of Translation Studies to get an idea of the range of such categories related to translation.

11. Even as I stake this position, it has to be mentioned that science does have a unique engagement with language. In the case of metaphors, too, there are characteristics that distinguish the use of metaphors in science and literature. For example, see Ortony (1979), Peterfreund (1990).

12. But there is also a unique relation which science establishes with the object, going beyond the satisfaction of having named the object. This has to do with what it does with it. It takes hold of what is named, touches it, grapples with and controls it. This explicit move towards 'touching' and 'controlling' (Hacking (1983) views this kind of activity as 'intervening') should be seen as a mode of intention that marks the uniqueness of scientific activity. This move is best exemplified by what is called technology. This idea of technology revolves around its ability to go beyond naming and into the domain of 'grasping.'

13. See Benjamin (1989, Chapter 4) for an insightful discussion on this idea of afterlife. See also Derrida (1985). 


\section{REFERENCES}

Bassnett-McGuire, S. (1991): Translation Studies. London and New York: Routledge, Revised Edition.

Benjamin, A. (1989): Translation and the Nature of Philosophy. London and New York: Routledge.

Benjamin, W. (1992): "The Task of the Translator," Illuminations. Trans. Harry Zohn, Fontana Press.

Buchwald, J. (1993): “Design for Experimenting,” World Changes, Horwich, (ed.), Cambridge: The MIT Press.

Crease, R. (ed.) (1997): Hermeneutics and the Natural Sciences. Dordrecht: Kluwer Academic Publishers.

Derrida, J. (1982): “White Mythology: Metaphor in the Text of Philosophy," Margins of Philosophy. Trans. Alan Bass, The Harvester Press Ltd.

Derrida, J. (1985): “Des Tours de Babel,” Difference in Translation. Ed. Joseph Graham, Ithaca: Cornell University Press.

Galison, P. (1997): Image and Logic. Chicago and London: University of Chicago Press.

Gentzler, E. (1993): Contemporary Translation Theories. London and New York: Routledge.

Gross, A. (1990): The Rhetoric of Science. Cambridge: Harvard University Press.

HACKING, I. (1983): Representing and Intervening: Introductory Topics in the Philosophy of Natural Science. Cambridge: Cambridge University Press.

Halliday, M. (1988): “On the Language of Physical Science," Registers of Written English, Ghadessey (ed.), Pinter Publishers.

Heelan, P. (1983): Space-Perception and the Philosophy of Science. Berkeley: University of California Press.

Jаковson, R. (1966): “On Linguistic Aspects of Translation,” On Translation, Reuben Brower (ed.), New York: Oxford University Press.

Kunn, T. (1970): The Structure of Scientific Revolutions. Chicago: University of Chicago Press, 1970.

Locke, D. (1992): Science as Writing. New Haven and London: Yale University Press.

Marsonet, M. (1995): Science, Reality and Language. Albany: SUNY Press.

Montgomery, S. (1996): The Scientific Voice. New York and London: The Guilford Press. Baker, M. (ed.) (1998): Routledge Encyclopaedia of Translation Studies. London: Routledge.

NidA, E.A. (1964): Towards a Science of Translating. Leiden: E.J. Brill.

Ortony, A. (ed.): Metaphor and Thought. Cambridge: Cambridge University Press.

Peterfreund, S. (ed.) (1990): Literature and Science: Theory and Practice. Boston: Northeastern University Press.

Popovic, A. (1976): A Dictionary for the Analysis of Literary Translation. Edmonton: University of Alberta.

Sankey, H. (1994): The Incommensurability Thesis. Aldershot: Avebury.

Steiner, G. (1975): After Babel. Oxford: Oxford University Press.

Venuti, L. (1998): The Scandals of Translation. New York and London: Routledge.

Wells, S. (1996): Sweet Reason: Rhetoric and the Discourses of Modernity. Chicago and London: The University of Chicago Press. 